\title{
Lichen aureus induced by an insect bite
}

\section{Emad Bahashwan}

\author{
Dermatology Division, Faculty of Medicine, Bisha University, Saudi Arabia \\ Corresponding author: Emad Bahashwan, MD, E-mail: Emad.a.bahashwan@gmail.com
}

\begin{abstract}
Lichen aureus is an uncommon variant of pigmented purpura and presents itself with a chronic and benign course. Clinically, lichen aureus cases are asymptomatic and are found in the lower limbs, presenting themselves as erythematous, brownish or golden macules and/or papules. Its diagnosis is based on clinical and histopathological findings. The prognosis of lichen aureus is generally good. A 34-year-old Filipino male presented himself with a single itchy skin lesion on the right leg present for three months. The lesion started as a small, round, reddish to brownish area and then increased in size over time. A history of an insect bite on the same site was reported. An examination revealed a single annular, golden to brownish macule on the right leg. Based on this clinical and histopathological feature, the skin lesion was diagnosed as lichen aureus. The comprehension of the pathogenesis of lichen aureus is essential for knowing its risk factors.
\end{abstract}

Keywords: Lichen aureus; Pigmented purpuric dermatosis; Insect bite

\section{INTRODUCTION}

Lichen aureus is a rare, clinical condition of the skin of unknown etiology. This skin condition belongs to the group of pigmented purpuric dermatoses, together with Schamberg pigmented purpura (progressive pigmentary dermatosis), Gougerot-Blum disease, Schamberg disease, purpura annularis telangiectodes (Majocchi's disease), lichen aureus, eczematid-like purpura of Doucas and Kapetanakis, and pigmented purpuric lichenoid dermatosis of Gougerot and Blum [1]. The histopathology of lichen aureus is characterized by chronic lymphocytic vasculitis with lichenoid lymphocytic infiltration with extravasated red blood cells (RBCs) in the early stage or hemosiderin deposition in the late stage. An increase in the number of blood vessels in the lichenoid infiltration distinguishes lichen aureus from the other variants of pigmented purpuric dermatosis [2].

\section{CASE REPORT}

A 34-year-old Filipino male, living in Saudi Arabia for six years, presented himself with a single itchy skin lesion on the right leg present for three months. The lesion started as a small, round, reddish to brownish lesion and then increased in size over time. A history of an insect bite on the same site was reported. No other significant health problems or family history of similar disorders were noted.

An examination revealed a single annular golden to brownish macule on the right leg (Fig. 1). No evidence of other skin diseases was noted, and no palpable lymph nodes in the popliteal and inguinal areas were found.

A skin biopsy was taken from which the histopathological findings of orthokeratosis, spongiosis, and lichenoid lymphohistiocytic infiltration without hydropic degeneration were found (Figs. 2a and 2b). An increase in the number of small blood vessels in the lichenoid infiltration, extravasated RBCs in the papillary dermis, and chronic endothelial injuries were also found (Figs. $3 \mathrm{a}$ and $3 \mathrm{~b}$ ).

Based on this clinical and histopathological feature, the skin lesion was diagnosed as lichen aureus.

The patient was treated with topical clobetasol propionate $0.05 \%$ cream twice daily for one month 


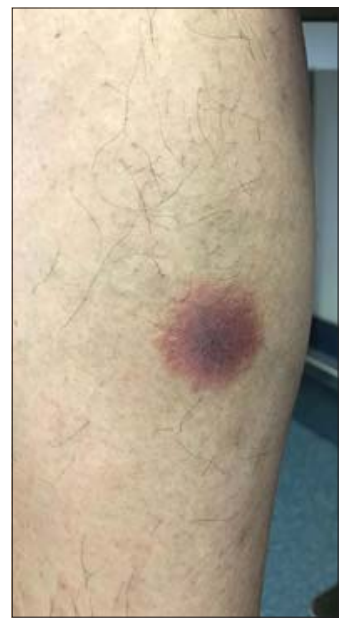

Figure 1: Golden to brownish plaque on the right leg.

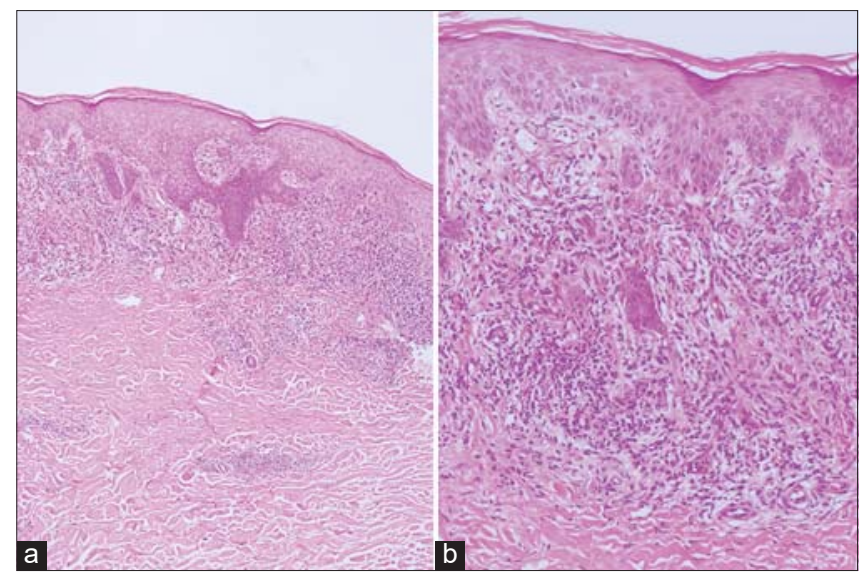

Figure 2: (a) Acanthotic epidermal lichenoid lymphocytic infiltrate (H\&E, 80x). (b) Lichenoid lymphocytic infiltrate without hydropic degeneration $(200 x)$.

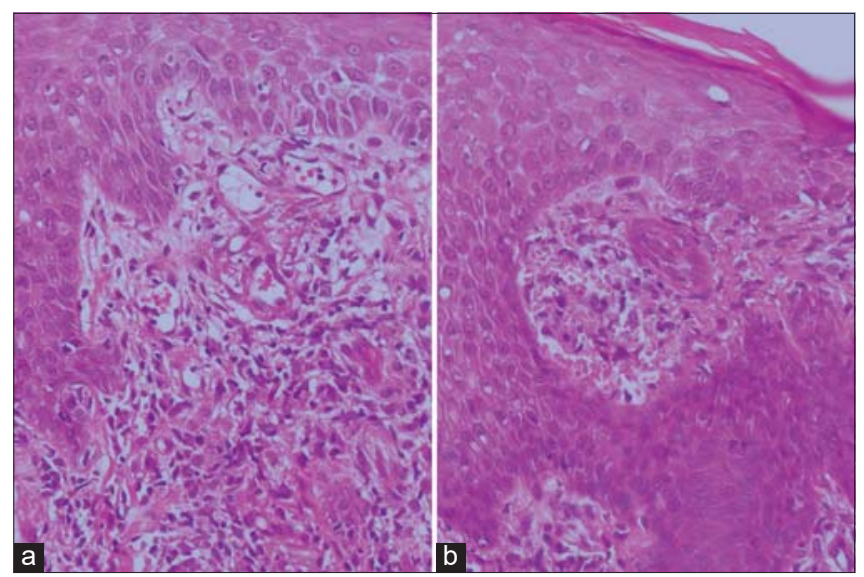

Figure 3: (a) Increased number and size of superficial blood vessels (400x). (b) Extravasated red blood cells (400x).

followed by topical mometasone $0.1 \%$ twice daily for one month, thereafter showing improvement.

\section{DISCUSSION}

LA was first described as lichen purpuricus in 1958 by Martin [3]. Its pathogenesis remains unclear, yet seems to be related to chronic inflammation of the capillaries in the papillary dermis, which could be triggered secondary to trauma, infections, drugs, and/ or venous insufficiency [4-6]. In this disorder, LA is usually characterized by a sudden onset of gold-colored skin lesions consisting of macules or patches, usually on the lower legs $[2,5]$. A skin biopsy may help confirm the diagnosis of LA as it presents itself with lichenoid lymphocytic infiltration with extravasated RBCs and hemosiderin deposition [2].

These lesions evolve slowly and usually persist unchanged for many years. Complete resolution rarely occurs [7]. The treatment of LA includes potent topical and systemic steroids, topical $0.1 \%$ ointment of pimecrolimus and tacrolimus, psoralen + UVA (PUVA), and/or narrowband UVB in addition to combination therapy with pentoxifylline and prostacyclin, all of which have shown variable results $[5,6]$.

In our case, the skin lesion of LA was induced by an insect bite, which has not been reported as a trigger of LA. A reaction to the insect bite may have induced micro-traumatic changes, which in turn could have led to chronic inflammation of small blood vessels, responding well to topical steroids.

\section{CONCLUSION}

Lichen aureus is a rare disease. More studies are needed to determine its pathogenesis, causes, and precipitating factors to prevent its occurrence or establish appropriate treatment.

\section{ACKNOWLEDGMENTS}

We would like to thank Dr. Hamza Alshehri and the histopathology department at Asser Central Hospital for providing histopathological information on the patient.

\section{Consent}

The examination of the patient was conducted according to the principles of the Declaration of Helsinki. 


\section{www.odermatol.com}

The authors certify that they have obtained all appropriate patient consent forms, in which the patients gave their consent for images and other clinical information to be included in the journal. The patients understand that their names and initials will not be published and due effort will be made to conceal their identity, but that anonymity cannot be guaranteed.

\section{REFERENCES}

1. Filho CRR, Schwartz J, Zanol J. ["Algesiogenic" lichen aureus] An Bras Dermatol. 2006;81:163-5.

2. Aung PP, Burns SJ, Bhawan J. Lichen aureus: An unusual histopathological presentation: A case report and a review of literature. Am J Dermatopathol. 2014;36:e1-4.

3. Martin RH. Case for diagnosis. Trans Rep St Johns Hosp Dermatol
Soc Lond. 1958;40:98.

4. Kanitakis C, Tsoïtis G. [Lichen purpuricus]. Ann Dermatol Venereol. 1982;109:445-52.

5. Murota H, Katayama I. Lichen aureus responding to topical tacrolimus treatment. J Dermatol. 2011;38:823-5.

6. Kim MJ, Kim BY, Park KC, Youn SW. A case of childhood lichen aureus. Ann Dermatol. 2009;21:393-5.

7. Price ML, Jones EW, Calnan CD, MacDonald DM. Lichen aureus: A localized persistent form of pigmented purpuric dermatitis. $\mathrm{Br}$ J Dermatol. 1985;112:307-14.

Copyright by Emad Bahashwan. This is an open access article distributed under the terms of the Creative Commons Attribution License, which permits unrestricted use, distribution, and reproduction in any medium, provided the original author and source are credited.

Source of Support: Nil, Conflict of Interest: None declared. 